\title{
Motor impairment in children 12 to 13 years old with a birthweight of less than $1250 \mathrm{~g}$
}

\author{
Andrew Powls, Nicola Botting, Richard W I Cooke, Neil Marlow
}

\begin{abstract}
Aim-To determine whether poor motor skills, previously identified in a cohort of very low birthweight $(<1250 \mathrm{~g})$ children, born in 1980-1, have persisted or improved. Previous assessments had shown significant improvement between the ages of 6 and 8 years.

Methods-The original cohort were traced and were assessed using the Movement Assessment Battery for Children, an update of the Test Of Motor Impairment, used at 6 and 8 years. Where possible the classroom-matched controls from the original studies were assessed, otherwise new controls were selected. Teachers were also asked to identify those children whom they considered clumsy. Forty seven of the original cohort of 53 children, all but one still attending mainstream school, and 40 original and 20 new classroom-matched controls were studied.
\end{abstract}

Results-Fifty one per cent of the cohort showed clinically important or borderline impairment. More of these children had significant impairment $(16 / 47,34 \%)$ than the controls $(3 / 60,5 \%)$. The improvement seen by 8 years of age was maintained but there was no further improvement. Girls had significantly higher overall impairment scores (median 16; interquartile range 10-21.5) than the boys $(5.5$ $(1 \cdot 5-12 \cdot 5))$, and on a wider variety of subtests $(5 / 8)$ than the boys $(3 / 8)$.

Conclusions-Many very low birthweight children have impaired motor skills. Despite early improvement it persists into adolescence and the deficit remains. Interventional studies may help to see if these problems can be alleviated.

(Arch Dis Child 1995; 73: F62-F66)

Keywords: clumsiness, impairment, school performance, preterm infants.

Institute of Child Health, Liverpool University, Alder Hey Children's Hospital, Eaton Road, Liverpool

A Powls

N Botting

R W I Cooke

Department of Child Health, Bristol Maternity Hospital, Bristol

N Marlow

Correspondence to: Dr Andrew Powls.

Accepted 6 May 1995
With the development of neonatal intensive care techniques over the past two decades, an increasing number of very low birthweight children survive. ${ }^{1}$ Of these, $80-90 \%$ are without major handicap and are able to attend mainstream schools alongside their normal birthweight peers, ${ }^{23}$ although some may have motor or sensory handicaps which require special provision. Attention has recently focused on the long term outcome of such children. There is evidence that despite their lack of major neurodevelopmental impairments, these children are failing to match the performance of their peers in a number of areas. These areas include their educational achievement, ${ }^{2-6}$ particularly reading and mathematics, ${ }^{346}$ social integration, ${ }^{7}$ and motor skills. ${ }^{4} 6$ 8-12

Several studies, ${ }^{6-11}$ using the test of motor impairment (TOMI-r), ${ }^{13}$ a standardised assessment of motor skills, have shown significantly impaired motor performance in very low birthweight children during their primary school education. It is not certain what happens to the motor skills of these children as they get older.

A cohort of very low birthweight children were assessed on two occasions, at 6 years and 8 years of age, by Marlow and colleagues. ${ }^{4} 8$ Both very low birthweight and control groups showed a significant improvement in their motor skills during the two year interval. The improvement in the very low birthweight group was greater than that of their controls, although the former still showed significantly poorer motor ability. This may suggest that their clumsiness improves as they get older.

To determine whether such initial improvement represents steadily maturing motor skills, although not yet matching the performance of their peers, we report a further controlled assessment of the same cohort of very low birthweight children aged 12 to 13 years.

\section{Methods}

The derivation of this cohort of children has been described in detail before. ${ }^{4}$ The children were all under $1251 \mathrm{~g}$ at birth and had all received intensive care at Mersey regional neonatal unit. All entered mainstream school and were without major neurodevelopmental impairment.

The controls from the previous studies were also traced. Where the original control was unavailable, the child's school was again asked to nominate a replacement of the same sex and nearest birthdate. Where the very low birthweight child and his/her original control were now at different schools, new controls were selected in a similar manner. This was to match for differing educational experience, because part of the wider study also included an educational assessment, which is not reported here. Both original and new controls were assessed as part of the study. One index child had moved to a special school and in this case only the original control was seen.

Informed written consent for all examinations were obtained from all families of control and index children, and from the schools and education authorities involved.

Where possible the children were assessed at their schools simultaneously with their 
Table 1 Results of Movement ABC for children

\begin{tabular}{llll}
\hline Item & $\begin{array}{l}V L B W \\
(n=47)\end{array}$ & $\begin{array}{l}\text { Controls } \\
(n=60)\end{array}$ & $\begin{array}{l}\text { Pvalue } \\
\text { (Mann-Whitney U test) }\end{array}$ \\
\hline $\begin{array}{l}\text { Manual dexterity items: } \\
\text { Peg turning }\end{array}$ & $1.0(0-3)$ & $0.0(0-1)$ & 0.009 \\
Cutting elephant & $1.0(0-4)$ & $0.0(0-0)$ & 0.0000 \\
Flower trail & $1.0(0-4)$ & $0.0(0-0)$ & 0.0002 \\
Ball skill items: & $0.0(0-1 \cdot 5)$ & $0.0(0-0)$ & 0.31 \\
Target throw & $0.0(0-1)$ & $0.0(0-0)$ & 0.005 \\
One hand catch & $0.0(0-2)$ & $0.0(0-0)$ & 0.01 \\
Static/dynamic balance items: & $1.0(0-2)$ & $0.0(0-2)$ & 0.13 \\
Board balance & $0.0(0-2)$ & $0.0(0-0)$ & 0.002 \\
Jump+clap & $10.0(3.5-16)$ & $2.5(0.5-6)$ & 0.0000 \\
Walk backwards & &
\end{tabular}

Data expressed as median impairment score (interquartile range). VLBW=very low birthweight.

contemporary controls. The original controls who were at different schools were also assessed at their schools as close as possible to the date of the index child's examination. A small number $(n=8)$ were seen at the Institute of Child Health where their school, or they themselves, had refused an examination at school.

All the children were tested using the Movement ABC for children. ${ }^{14}$ This is an update of the Test of Motor Impairment ${ }^{13}$ used in the previous studies. To maintain the comparability with the old test it still comprises eight tasks, three of manual dexterity, two of ball skills, and three of static and dynamic balance. For each age band the same range of skills is tested. At this age the tests comprise ${ }^{14}$ : Manual dexterity (1) Speed and sureness of movement - inverting 12 pegs in a board with one hand as quickly as possible (both hands are tested).

Manual dexterity (2) Coordination of two hands to perform a single task - accurately cutting out a complex shape (an elephant).

Manual dexterity (3) Hand-eye coordination tracing round a complex shape (a flower).

Ball skills (1) Throwing - a tennis ball at a target 2.5 metres away.

Ball skills (2) Catching - a tennis ball thrown against a wall using one hand (both hands are tested).

Balance (1) Static balance - standing on a raised strip 1 inch wide on wooden boards.

Balance (2) Dynamic balance during explosive movements - clapping as many times as possible while jumping over a low jump.

Balance (3) Dynamic balance during slow controlled movements - walking backwards, heel to toe, along a line.

Each subtest is assigned an impairment score on a six point scale $(0-5)$. As it is a test of impairment rather than of skill, only the performances of the most impaired $15 \%$ of the population are assigned a score of greater than zero. This scoring system permits greater differentiation between children with moderate to severe motor difficulties than was possible with the original scoring system of the Test Of Motor Impairment which used a three point (0-2) scoring system. It is possible, however, to assign a score for each subtest using both scoring systems to allow for longitudinal comparison. For our testing we recorded impairment scores using both systems.

In this assessment all the children were tested using the oldest age band of the test (band 4). Although a number of our children were older than 12, the oldest age for which this set of tests was standardised; in the context of a controlled study the test represented a fair comparison of skills.

As part of a broader educational questionnaire the maths, English, and form teachers were also asked to say whether they considered the children to be clumsy using a simple yes/no scale. This was to compare their perception of the child's motor skills with the results of formal testing, to see whether motor impairment can be identified in an informal way in the classroom. The children were rated as clumsy if any of the three teachers identified a problem in this area.

The results were analysed using SPSS/PC + . The results from both study periods were merged with the present data and analysed using non-parametric statistical methods; the continuous data were analysed using the Mann Whitney- $U$ test and frequencies using the $\chi^{2}$ test.

\section{Results}

Since the study at 8 years two children have emigrated and two further families refused a further examination. Therefore, 47 of the original cohort of 53 children were seen and assessed at 12 to 13 years of age. One of our original cohort had moved to a special school.

Forty of the original controls from both assessments were seen. Of the other eight controls, three refused further examination and the remainder failed to reply to our letters. Twenty new controls were selected by their schools.

The very low birthweight children had higher impairment scores than their normal birthweight peers on all eight elements of the test (table 1). This was significant in six subtests (Mann-Whitney U) but not in 'throwing at a target' and 'jumping and clapping'. The most significant differences were seen in the tests of manual dexterity. The scoring system, whereby only the performances of the least

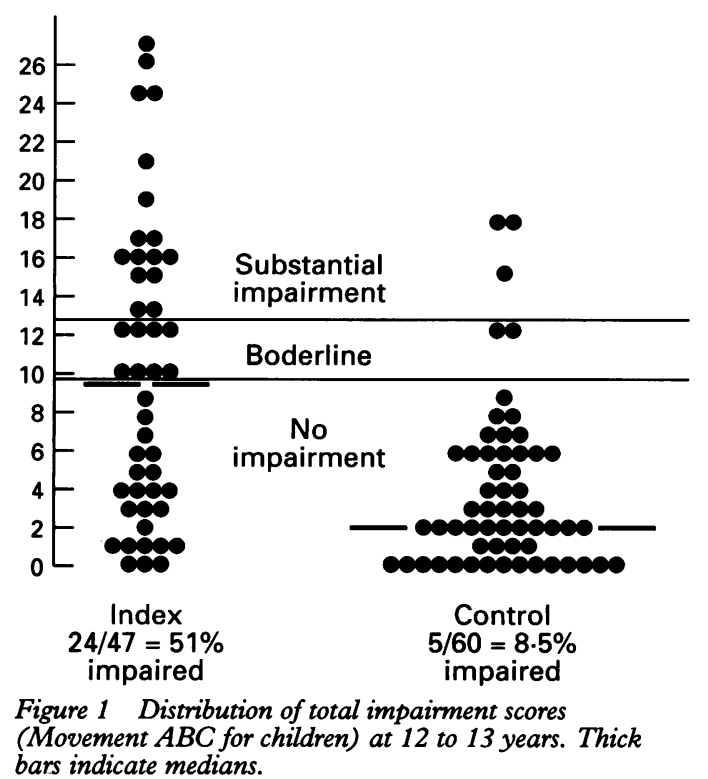


Table 2 Total impairment score (Test of Motor Impairment) at 6, 8, and 12 to 13 years

\begin{tabular}{|c|c|c|c|c|c|}
\hline & 6 Years & 8 Years & & $12-13$ Years & \\
\hline VLBW & $\begin{array}{l}6 \cdot 0(4-8 \cdot 75) \\
(n=51)\end{array}$ & $\begin{array}{l}3 \cdot 5(3-5) \\
(n=50)\end{array}$ & ${ }^{\star} \mathrm{P}=0.0001$ & $\begin{array}{l}4 \cdot 0(1 \cdot 5-6 \cdot 5) \\
(n=47)\end{array}$ & $\begin{array}{l}{ }^{\star} \mathrm{P}=0.0000 \\
+\mathrm{P}=0.54\end{array}$ \\
\hline Controls & $\begin{array}{l}3 \cdot 0(1 \cdot 5-4 \cdot 5) \\
(n=52)\end{array}$ & $\begin{array}{l}2 \cdot 0(1-4) \\
(n=47)\end{array}$ & ${ }^{\star} \mathrm{P}=0.16$ & $\begin{array}{l}1 \cdot 0(0-2) \\
(n=40)\end{array}$ & $\begin{array}{l}{ }_{\star} \mathrm{P}=0.008 \\
+\mathrm{P}=0.29\end{array}$ \\
\hline
\end{tabular}

Data expressed as median impairment score (interquartile range).

$\star P$ value difference from 6 year score; $† P$ value difference from 8 year score (Wilcoxon paired rank test). Control scores analysed only where two paired scores available.

$6 / 8$ comparison $(n=46$ pairs); $6 / 12$ comparison ( $n=35$ pairs); $8 / 12$ comparison ( $n=40$ pairs).

$6 / 8$ comparison $(\mathrm{n}=46$ pairs $) ;$
VLBW $=$ very low birthweight.

able $15 \%$ of the population score greater than zero on each item, ensures that the median score for each subtest was low. The differences are produced by an excess of poor scores in the index group.

Overall impairment scores were significantly higher in the index group (median 10.0; interquartile range $3 \cdot 5-16)$, compared with their controls $(2.5(0.5-6) ; \mathrm{P}<0.0001$; MannWhitney $U)$. The distribution of overall impairment scores is illustrated in fig 1 .

Movement ABC impairment scores of 10.0-13.0 are regarded as borderline impairment (5th to 15 th percentile), and scores greater than 13.0 as significant motor impairment ( $<5$ th percentile). Of our index group, $24 / 47(51 \%)$ scored 10 or more compared with $5 / 60(8.5 \%)$ of our controls $\left(\chi^{2}=24, \mathrm{df}=1\right.$, $\mathrm{P}<0.0001) ; 16 / 47$ (34\%) scored 13.5 or more compared with $3 / 60(5 \%)$ of our controls $\left(\chi^{2}=15 \cdot 2, \mathrm{df}=1, \mathrm{P}=0.0001\right)$.

The girls in our very low birthweight group performed significantly worse than the boys. Their median overall impairment scores (interquartile range) were $16(10-21 \cdot 5)$ for the girls compared with $5.5(1.5-12.5 ; \mathrm{P}=0.008)$ for the boys. The girls also scored significantly worse than their controls on a wider range of subtests $(5 / 8)$ than the boys $(3 / 8)$. These were the three manual dexterity items and the two balance items for the girls contrasting with only cutting, tracing, and catching for the boys.

We used the three point scoring system of the original test (TOMI-r) to analyse longitudinal performance in the index children and

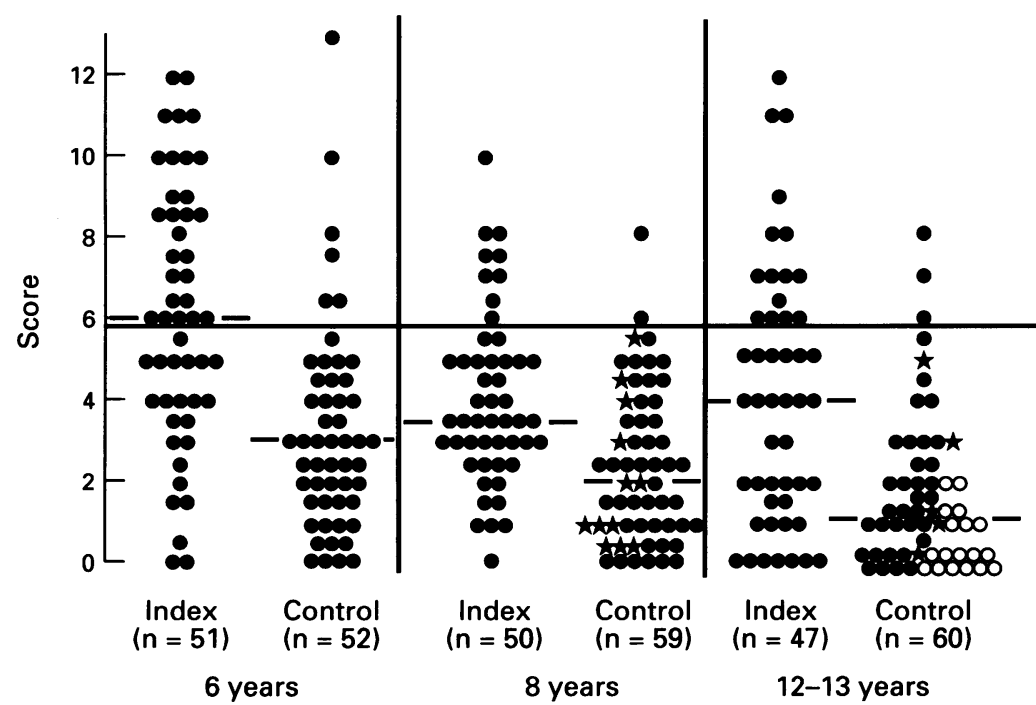

Figure 2 Distribution of total impairment scores (Test of Motor Impairment) at 6, 8, and 12 to 13 years. Asterisks indicate new controls recruited at 8 years. Open circles indicate new controls recruited at 12 years. Horizontal line indicates standardisation cutoff for significant impairment. Thick bars indicate median scores. those controls seen on more than one occasion. As previously noted, the very low birthweight children's scores had significantly improved from 6 years of age $($ median $=6)$ to 8 years of age (median $=3.5 ; \mathrm{P}<0.0001$ ). This improvement was maintained but there was no further fall in their scores by the age of 12 to 13 years (median $=4 \cdot 0$; difference from 8 year score $P=0.54)$. A similar picture was seen in the controls (table 2).

The distribution of scores (figure 2) remained comparable except for a slight increase in scores of zero. The six year and 8 year scores from the Test of Motor Impairment were predictive of the Movement ABC scores at 12 to 13 years, both showing significant correlations ( $r$-values being 0.54 and 0.52 , respectively, both $P<0.001$ ).

In the very low birthweight group tracking of an individual's overall impairment scores from 6 years to 12 to 13 years was fairly consistent for the children in the non-impaired group at 6 years. Only three $(14 \%)$ children showed large increases ( 3 or more points) resulting in them changing to the significantly impaired group by 12-13 years (one boy and two girls). Among those very low birthweight children with high impairment scores at 6 years of age the tracking was reliable among the girls but less reliable among the boys. Of the children in the worst quartile - those with scores of 8.5 or more, eight out of 15 children did make large improvements (more than 3 points), and were no longer in the impaired group at 12 to 13 years. Such improvements were more likely among boys than girls $(7 / 9$ boys $v 1 / 6$ girls; $\mathbf{P}<0.07$; Fischer's exact test, two tailed). Impairment scores at 8 years were less reliable, overall, for tracking of an individual's performance.

The correlation between motor scores with a range of perinatal variables was examined. Univariate analysis showed no significant associations (table 3).

The two groups were compared for a range of demographic variables that may affect performance. There were no significant group differences found for age at examination, maternal or paternal education, housing status, income, occupational status, or for single parent families. Differences were found in the number of siblings and rank, the index children tending to be first children and to have fewer siblings. These differences are commonly found in studies of premature children and should work in their favour.

The results of the teacher questionnaires showed little correlation between the teachers' subjective opinions of the children's motor skills and the results of objective testing. The teachers rated more very low birthweight children as appearing clumsy (14/47, 30\%), compared with our controls $(8 / 60,13 \%)$. However, the 15 index children in the group with significant motor impairment, as defined by the Movement $\mathrm{ABC}$, were equally likely to be rated clumsy $(n=7)$ as not clumsy $(n=8)$ by their class teachers. Of the index children rated as clumsy, only seven of $14(50 \%)$ were found to have significant impairment on testing with Movement ABC. 
Table 3 Perinatal variables and motor impairment

\begin{tabular}{lccc}
\hline & $\begin{array}{l}\text { No motor } \\
\text { impairment } \\
(n=23)\end{array}$ & $\begin{array}{l}\text { Borderline } \\
(n=8)\end{array}$ & $\begin{array}{l}\text { Significant } \\
\text { impairment } \\
(n=16)\end{array}$ \\
\hline Twins & $6(26)$ & $2(25)$ & $4(25)$ \\
Antenatal steroids & $8(34)$ & $1(12)$ & $4(25)$ \\
$\beta_{2}$ agonists & $12(52)$ & $1(12)$ & $6(37)$ \\
Breech & $7(30)$ & $2(25)$ & $3(19)$ \\
Caesarean & $11(48)$ & $4(50)$ & $3(19)$ \\
Intubated at birth & $3(13)$ & $3(37)$ & $3(19)$ \\
Apgar score 1 minute & $5(3-8)$ & $7(2 \cdot 5-8)$ & $4(1-7)$ \\
Apgar score 5 minutes & $9(6-10)$ & $9(7-10)$ & $8(7-9)$ \\
Birthweight (g) & $1055(810-1250)$ & $1090(630-1240)$ & $1050(620-1240)$ \\
Gestation (weeks) $\dagger$ & $28(25-34)$ & $31(26-33)$ & $28(25-35)$ \\
Small for dates (SD from & $-0 \cdot 5(-3 \cdot 8-2 \cdot 2)$ & $-1 \cdot 2(-2 \cdot 9-0 \cdot 5)$ & $-0 \cdot 8(-2 \cdot 9-0 \cdot 4)$ \\
$\quad$ normal) $\dagger$ & $2(0-28)$ & $2(0-3)$ & $1 \cdot 5(0-24)$ \\
Time ventilated (days) $\dagger$ & $5(22)$ & $1(12)$ & $5(31)$ \\
Bruised & $2(9)$ & $1(12)$ & $3(19)$ \\
Sepsis & $3(13)$ & 0 & $1(6)$ \\
Abnormal movements & $4(17)$ & 0 & $2(12)$ \\
Fits & $8(35)$ & $2(25)$ & $6(37)$ \\
Intraventricular haemorrhage & $3(13)$ & 0 & $2(12)$ \\
Periventricular leucomalacia & & & \\
\hline
\end{tabular}

Data shown as numbers (\%) except ${ }^{\star}$ median (interquartile range), fmedian (range).

\section{Discussion}

It is evident from a number of recent studies that survivors of modern neonatal intensive care who have otherwise escaped major neurodevelopmental handicap and have reached mainstream education are not matching their peers' performance in a number of areas. $^{2-12}$ Poor motor skills have been of particular concern as they are not only associated with impaired educational achievement ${ }^{5}$ but may also be the best predictor of subsequent school performance. ${ }^{3}$

All the studies of motor impairment in very low birthweight intensive care graduates so far have been in children of primary school age, and the natural history of these impairments as the children approach adolescence and enter secondary education is unknown. Repeated testing of this cohort at 6 years and at 8 years $^{38}$ suggested an improvement over a two year interval. Other studies of poor motor skills in the normal school population, however, have suggested that these problems may persist and be associated with deteriorating school performance, poor self-esteem, and behavioural disorders. ${ }^{15-17}$

Our study shows that the early improvement in motor skills seen in this cohort has not continued, with no further improvement in overall impairment scores and a continuing difference between their performance and that of their peers. Fifty one per cent of the group showed some impairment of their motor skills, 34\% showing significant impairment, as they enter adolescence. This is a time when many new skills will be required as their curriculum broadens in scope. The differences appear to be greatest in the tasks involving manual dexterity, for both sexes, plus tasks involving dynamic balance in the girls.

The reason for the difference between the sexes is unclear. The girls may be more susceptible to some unidentified adverse perinatal event, or they may be more likely to survive such adverse perinatal events and reach follow up. Conversely, it may be that boys receive greater input in the development of physical skills, through greater involvement in sports and other physical activities, which may show up in improvement of their gross motor skills.
This possibility may be supported by our finding that among those rated as impaired at 6 years, boys are more likely to improve significantly their scores by 12 to 13 years.

Unlike Levene et $a l^{9}{ }^{9}$ who found that impairment scores correlated with cranial ultrasound abnormalities, and Mutch et al, ${ }^{18}$ who found an association with birthweight, we found no correlation between any perinatal factors and impairment scores. The differences therefore may relate either to subtle neurological lesions too small or too diffuse to be detected by ultrasound scanning (or at least by ultrasound scanning of the definition available in 1980-81). Alternatively, they may relate to other factors such as reduced sensory input due to hearing and visual defects, or to subsequent developmental influences such as parenting skills. This present report is part of a much broader assessment of this cohort designed to address these possibilities.

Our results concur with those of Michelsson et $a l^{5}$ who showed that early objective measures of motor impairment correlate significantly with repeated measures in later childhood and are therefore useful as a screen for possible intervention in this group. Such intervention may be particularly important in girls who seem to be at greater risk of permanent impairment. Formal screening may be important as our.study would suggest that their poor motor skills are not being identified in the school classroom.

The teachers did rate significantly more of the very low birthweight children as clumsy and this may indicate that they do recognise that these children have more problems than their peers. They did not, however, accurately identify those whose problems arise from motor impairments. Although physical education teachers were not questioned, the greatest problems were in the manual dexterity tasks which would be more evident in the classroom. Intervention based on the teachers assessments would have failed to reach many of the children who may have benefited, as well as including many children without motor impairment, as defined by the Movement ABC.

Schoemaker et al ${ }^{19}$ described a programme of exercises performed by physiotherapists (although they could equally well form part of a normal programme of physical education in a school setting) which produced a significant improvement in the overall impairment scores of a group of clumsy children. The exercises were based on the need to improve such children's proprioceptive/kinaesthetic perception (awareness of how they should move), as well as improving their confidence and selfcontrol. It would be useful to investigate a similar intervention programme in very low birthweight children with motor difficulties to see if this could ameliorate these children's clumsiness.

It would seem appropriate for very low birthweight children to have access to forms of physical education that encourage movement skills without placing too great an emphasis on competition, as repeated failure at competitive 
sports may well lead to the children withdrawing from all physical activity. Screening of these children in primary school might help the teachers to plan a programme of physical education tailored to the specific difficulties of the individual.

Our study shows that poor motor skill in very low birthweight children at school age is a common problem and that it persists as they grow older. Previous work has found that such impairments are associated with failure in other areas of educational development ${ }^{4}$ and poor self-esteem in the affected children. ${ }^{7}$ Indeed, such impairments may be more problematic for these children in early adolescence, as the curriculum introduces a wide range of new activities which may highlight their lack of motor skills. We believe that these findings suggest the need critically to assess intervention strategies in very low birthweight children at risk of motor impairment.

We thank Mrs S Longworth and Mrs D Bolger for secretarial assistance, and the schools who gave of their time and facilities for our assessments.

1 Alberman E, Botting B. Trends in prevelance and survival of very low birthweight infants, England and Wales: 1983-7. Arch Dis Child 1991; 66: 1304-8.

2 Eilers BL, Desai NS, Wilson MA, Cunningham MD. Classroom performance and social factors of children with birthweights of 1250 grams or less: follon years of age. Pediatrics 1986; 77: 203-8.

3 Marlow N, Roberts BL, Cooke RWI. Outcome at 8 years for children with birth weights of $1250 \mathrm{~g}$ or less. Arch Dis Child 1993; 68: 286-90.

4 Zubrick SR, Macartney H, Stanley FJ. Hidden handicap in school-age children who received neonatal intensive care. Dev Med Child Neurol 1988; 30: 145-52.
5 Michelsson K, Lindahl E, Parre $M$, Helenius $M$. Nine year follow up of infants weighing $1500 \mathrm{~g}$ or less at birth. Acta Paediatr Scand 1984; 73: 835-41.

6 Nickel RE, Bennett FC, Lamson FN. School performance of children with birthweights of $1000 \mathrm{~g}$ or less. $A m \mathcal{f D}$ Child 1982; 136: 105-10.

7 Hoy EA, Sykes DH, Bill JM, Halliday HL, McClure BG, Reid MM. The social competence of very low birthweight children: Teacher, peer and self-perceptions. $\mathcal{F}$ Abnormal Child Psychol 1992; 20: 123-50.

8 Marlow N, Roberts BL, Cooke RWI. Motor skills in extremely low birthweight children at the age of 6 years. Arch Dis Child 1989; 64: 839-47.

9 Levene MI, Dowling S, Graham M, Fogelman K, Galton $M$. Impaired motor function (clumsiness) in 5 year old children: correlation with neonatal ultrasound scans. Arch Dis Child 1992; 67: 687-90.

10 The Scottish Low Birthweight Study Group. The Scottish low birthweight study I: Survival, growth, neuromoto and sensory impairment. Arch Dis Child 1992; 67 675-81.

11 Pharoah POD, Stevenson CJ, Cooke RWI, Stevenson RC. Clinical and subclinical deficits in a geographically defined cohort of low birthweight infants. Arch Dis Child 1994; 70: 264-70.

12 Saigal S, Rosenbaum P, Szatmari P, Campbell D. Learning disabilities and school problems in a regional cohort of extremely low birth weight $(<1000 \mathrm{~g})$ children: A comparison with term controls. Developmental and Behavioural paediatrics 1991; 12: 294-300.

13 Stott DH, Moyes FA, Henderson SE. Henderson revision of the Stott-Moyes-Henderson Test of Motor Impairment. the Stott-Moyes-Henderson Test of Motor Impait

14 Henderson S, Sugden D. Movement Assessment Battery for Children. London: Psychological Corporation, 1992.

15 Losse A, Henderson SE, Elliman D, Hall DB, Knight E, Jongmans $M$. Clumsiness in children - do they grow ou of it? A ten year follow up study. Dev Med Child Neurol 1990; 32: 1099-122.

16 Henderson SE, Knight E, Losse A, Jongmans M. The clumsy child in school are we doing enough? Br f Phys Ed 1991; (Research suppl 3): 2-8.

17 Henderson SE, Hall DB. Concomitants of clumsiness in young children. De Med Child Neurol 1982; 24: 448-60.

18 Mutch L, Leyland A, McGee A. Patterns of neuropsychological function in a low-birthweight population. Dev Med logical function in a low-birthwe.

19 Schoemaker MM, Hijilkema MGJ, Kalverboer AF Physiotherapy for clumsy children: An evaluation study. Dev Med Child Neurol 1994; 36: 143-55. 